\title{
Feasibility of a Dual Neurosurgeon- Scientist Career in Canada: A Survey Study
}

\author{
Fady Girgis
}

\begin{abstract}
Objectives: Performing 'good work' in either neurosurgery or neuroscience alone is a challenge. Despite this, a large number of neurosurgeons divide their careers between the two fields, and attempt to excel in both arenas simultaneously. The purpose of this study is to explore perceptions on whether it is possible to do good work in both neurosurgery and research simultaneously, or whether one field suffers at the expense of the other. Methods: This question was put to practicing neurosurgeons via an electronic survey that was distributed to resident and staff neurosurgeons in Canada. Results: 54 surgeons completed the survey, 32 of whom were current or intended neurosurgeon-scientists. Themes explored through the survey included motives behind the pursuit or absence of research in one's neurosurgical career, the quality and feasibility of a dual career, and alternatives to one individual assuming a dual role. Conclusions: The opinions obtained revealed that it is possible to do good work in both neurosurgery and neuroscience simultaneously, but in reality it is very difficult to do. Alternatives to this dual career, such as collaboration between clinical neurosurgeons and pure scientists for example, may help bridge the gap between clinical and research arenas.
\end{abstract}

RÉSUMÉ: Enquête sur la faisabilité d'une double carrière de neurochirurgien et de chercheur au Canada. Objectifs : Faire du « bon travail » en neurochirurgie ou en neurosciences présente un défi. En dépit de ce fait, un grand nombre de neurochirurgiens partagent leur carrière entre ces deux champs d'expertise et tentent d'exceller dans les deux champs simultanément. Le but de cette étude était d'explorer les perceptions au sujet de la possibilité de faire du bon travail simultanément en neurochirurgie et en recherche ou si l'un en souffre aux dépens de l'autre. Méthode : Nous avons posé la question à des neurochirurgiens en pratique active lors d'une enquête par voie électronique distribuée aux résidents et aux neurochirurgiens en pratique active au Canada. Résultats : Cinquante-quatre chirurgiens ont complété l'enquête, dont 32 étaient ou avaient l'intention d'être des neurochirurgiens-chercheurs. Les thèmes explorés au moyen de l'enquête couvraient les motifs qui incitaient les neurochirurgiens à poursuivre une carrière en recherche ou au contraire à ne pas le faire, la qualité et la faisabilité d'une double carrière et les alternatives à ce qu'un même individu assume les deux rôles. Conclusions : Les opinions exprimées ont révélé qu'il est possible de faire du bon travail simultanément en neurochirurgie et en neurosciences, mais qu'en réalité il s'avère très difficile de la faire. Les alternatives à cette double carrière, telle la collaboration entre les neurochirurgiens cliniques et les chercheurs en sciences fondamentales par exemple, peuvent aider à combler l'écart entre le domaine de la clinique et celui de la recherche.

Can J Neurol Sci. 2013; 40: 504-511

Neurosurgery is predominantly a clinical specialty, both historically and presently ${ }^{1,2}$. Despite this, people with an interest in the advancement of clinical practice through research have frequently been attracted to the profession. As such, several neurosurgeons wear 'two hats' by devoting a significant portion of their time to basic science or epidemiological research while continuing to perform clinically. These individuals are classified as neurosurgeon-scientists.

The purpose of having a single person span both clinical and research fields is logical: Clinician-scientists form a bridge that links clinical practice with basic science research. It is in this way that patient issues can be brought to the research bench in a practical and goal-oriented manner which will, in turn, lead to significant clinical contributions ${ }^{3,4}$. Specifically in neurosurgery, 'it is our positions in the trenches that make neurosurgeons singularly qualified to ask the right questions about nervous system function and dysfunction.' ${ }^{5}$

While most would agree that neurosurgeons are in the best position to ask the right questions about clinical disease, because they deal directly with the diagnosis, treatment and outcomes of patients with these diseases, some would disagree that neurosurgeons are in the best position to answer those questions. Several obstacles make the lives of neurosurgeon-scientists more difficult, leading some to go so far as to question the potential extinction of those with this dual career ${ }^{6,7}$. Time constraints, bureaucracy, financial priorities, and rapid advances in basic science ${ }^{8-11}$ are all factors that are forcing current and future neurosurgeon-scientists to re-examine their dual roles as clinicians and researchers, and ultimately re-define their priorities in order to perform effectively in both fields.

From the Department of Neurosurgery, Foothills Medical Centre, Calgary, Alberta, Canada.

Received May 16, 2012. Final Revisions Submitted February 20, 2013. Correspondence to: Fady Girgis, 12th Floor, Foothills Medical Centre, 140329 Street NW, Calgary, Alberta, T2N 2T9, Canada. Email: fadygirgis@yahoo.com. 
Successful performance in clinical and research arenas has been previously explored in the literature. First, in clinical medicine, several studies have defined what it means to be a 'good doctor', both from physician and patient perspectives. Patients tend to value strong communication and interpersonal skills, a sense of caring, the ability to form a trusting patientdoctor relationship, and a skilled technician when it comes to surgery ${ }^{12,13}$. Contrastingly, the values doctors themselves associated with good clinical practice were competence in medical knowledge as first and foremost, followed by patientdoctor interpersonal skill, teaching skill, and camaraderie ${ }^{14,15}$.

Second, in scientific research, the definition of 'good work' has evolved from one of quantitative indicators and peer review in the 1990's, to one of core values and responsibilities in the present. Sonnert ${ }^{16}$ assessed top biologists at several prestigious universities and concluded that annual publication productivity rate, the number of solo-authored publications, and graduate school prestige were the strongest predictors of excellence in the basic sciences. More recently, several geneticists were interviewed through the GoodWork Project ${ }^{17}$ for their opinions as to what defined good work in science research. In contrast to the more tangible characteristics identified by Sonnert, the ideas distilled from Gardner's study were more focused on responsibility towards society, the profession, the public, and oneself.

Although these definitions are perceptual in that they were gleaned using subjective data acquisition methods, such as survey and questionnaire formats, they form a foundation on which to build similar characterizations in the field of neurosurgery. This study uses a similar social science approach to further describe the concept of 'good work' in neurosurgery and neuroscience, and through the opinions of currently practicing resident and attending neurosurgeons in Canada, it aims to assess the feasibility of excelling in both fields simultaneously.

\section{Methods}

All neurosurgical program directors in Canada were contacted by email and invited to distribute an electronic survey to the staff and resident members of their departments. The invitation indicated that a study was being conducted to investigate the role of research in modern day neurosurgery, with a link to the online survey included in the message. In order to maximize response rates, the survey was brief, electronic, and anonymous.

The concept of good work in clinical and research arenas is somewhat abstract, making the quantitative measure of its defining criteria difficult. Therefore, a qualitative research approach was chosen. More specifically, a survey method was employed in order to reach the largest number of residents and staff surgeons possible. Questions were designed to probe for specific qualities that exemplified ideal neurosurgical practice in relation to research. For this study, the designation of neurosurgeon-scientist was defined as a neurosurgeon who spends at least $50 \%$ of his or her time performing research or research-related activities, a designation that was decided upon by the individual completing the survey based on their current work habits. In the case of residents, the designation was assigned based on intended practice, rather than current practice.
The author developed the survey and tested it on four clinical colleagues to ensure ease of understandability, flow of questions, and relevance of content. It consisted of four separate parts: The first section was for the collection of demographic information. The second section was solely for current or intended neurosurgeon-scientists and focused on vocational motivations and responsibilities. The third section had a similar focus but was solely for those who were not, or did not intend to become, neurosurgeon-scientists. The final section used different questioning methods to explore a spectrum of perceptions on research in neurosurgery which included the feasibility of a dual career, alternatives to a dual career, the quality of research and clinical practice when pursued simultaneously, and how research ability fits into the attributes esteemed by current practitioners.

Statistical analysis was performed on the survey results using analysis of variance (ANOVA) and Pearson chi-squares testing. In the case of multiple comparisons, post-hoc tests included pairwise comparisons using the Bonferroni method. Power calculations were done using likelihood ratio chi-squares testing.

\section{RESULTS}

\section{Participants}

Of the ten program directors contacted, eight forwarded the survey to their departments, with 138 residents and staff surgeons reached. Of these 138, 54 filled out the survey, giving a response rate of $39.1 \%$, equally divided between residents and staff neurosurgeons $(27 / 54,50 \%$ each group). The average postgraduate year for resident respondents was 4.1, with a range of one to nine. For attending surgeons, the average number of years in practice since finishing residency was 11.0 , with a range one to thirty. Forty-one of the 54 resident and staff participants (75.9\%) had greater than one year of formal research training, with 30 of these possessing a Master's or PhD degree. Seventeen of $27(65.4 \%)$ of the attending surgeon respondents worked in an academic center and received payment through salary, while the rest received payment through a fee-for-service model either at an academic center or a community hospital.

\section{Research demographics}

In this study, the designation of neurosurgeon-scientist was defined as a neurosurgeon who spent, or intended to spend in the case of residents, at least fifty percent of his or her time performing research or research related activities. With this in mind, $60.4 \%(32 / 54)$ of respondents described themselves either as current or intended neurosurgeon-scientists, with $46.9 \%$ of these (15/32) having decided on this career path during residency and $53.1 \%$ of these (17/32) having decided before beginning residency. Twenty-one of the $32(65.6 \%)$ conducted basic science research and 11 of the $32(34.4 \%)$ conducted clinical and/or epidemiological research. Furthermore, of those currently conducting research, $45.8 \%$ are performing this research in the same area as that in which they completed their research training and $50.0 \%$ are researching in an area that they have described as similar to their initial training. Only $4.2 \%$ of neurosurgeon-scientists are doing research in a field unrelated to their area of initial research training. 


\section{Comparisons between neurosurgeons and neurosurgeon- scientists}

Current and intended neurosurgeon-scientists ranked several reasons for including research as a substantial part of their careers, with the results found in Figure 1. As can be seen in the figure, the reason awarded the highest importance was a genuine interest in research, followed by a desire to help one's patients, obtaining a good job after residency, and embracing the prestige associated with being a surgeon scientist. One-way ANOVA showed that the weightings differed significantly across the four responses, $\mathrm{F}(3,128)=39.62, \mathrm{p}<0.001$. Bonferroni post-hoc comparisons of the four groups indicated that all comparisons were statistically significant at the 0.05 level of significance, except for the comparison between good job $(\mathrm{M}=2.79)$ and patients $(\mathrm{M}=3.03), \mathrm{p}=0.651$.

Similarly, current and intended non-research neurosurgeons ranked several reasons for not including research as a substantial part of their careers, with the results found in Figure 2. As can be seen in the figure, the reason awarded the highest importance was time constraints, followed by strong competition for grant funding, extended length of training, risk of sacrificing one's technical abilities at the expense of research abilities, and the increasing complexity of science. Although one-way ANOVA showed that in general the weightings differed significantly across the four responses, $\mathrm{F}(5,120)=7.15, \mathrm{p}<0.001$, Bonferroni post-hoc analysis showed that only certain specific comparisons reached statistical significance. These included: time constraints $(M=3.38)$ and money $(M=1.76), p<0.001$; time constraints and complexity of science $(\mathrm{M}=2.24), \mathrm{p}=$
0.002; money and grant competition $(\mathrm{M}=2.76), \mathrm{p}=0.011$; and money and sacrifice of technical skill $(\mathrm{M}=2.76), \mathrm{p}=0.011$.

Both scientist and non-scientist residents and staff were then compared with regard to whom or what they felt most responsible to in their careers, with the results found in Figure 3. Overall, both groups felt most responsible to their patients and least responsible to the profession of neurosurgery. Although the two groups differed slightly in their responsibility weightings for each category, statistical analysis using two way ANOVA showed these differences were insignificant, $\mathrm{F}(3)=1.56, \mathrm{p}=$ 0.1992 .

\section{Collaboration in research}

Forty-six of $54(85.2 \%)$ resident and staff respondents felt that neurosurgeons who collaborate with basic scientists to conduct research are equally or more likely to obtain meaningful results compared to neurosurgeon-scientists conducting the same research. Although more neurosurgeons $(95.2 \%)$ were in favor of collaboration compared to neurosurgeon-scientists $(78.8 \%)$, this difference was not significant, $\mathrm{x}^{2}(1)=2.752, \mathrm{p}=0.097$.

Further stressing a role for collaboration and teamwork, $90.7 \%$ of resident and staff respondents (49/54) felt that most neurosurgeon-scientists ask research questions that are more clinically relevant than pure, non-MD basic scientists. Along the same lines, only $9.3 \%(5 / 54)$ of those surveyed felt that most neurosurgeon-scientists are generally better researchers than basic scientists. Conversely, 57.4\% (31/54) felt that basic scientists are better researchers than neurosurgeon-scientists.

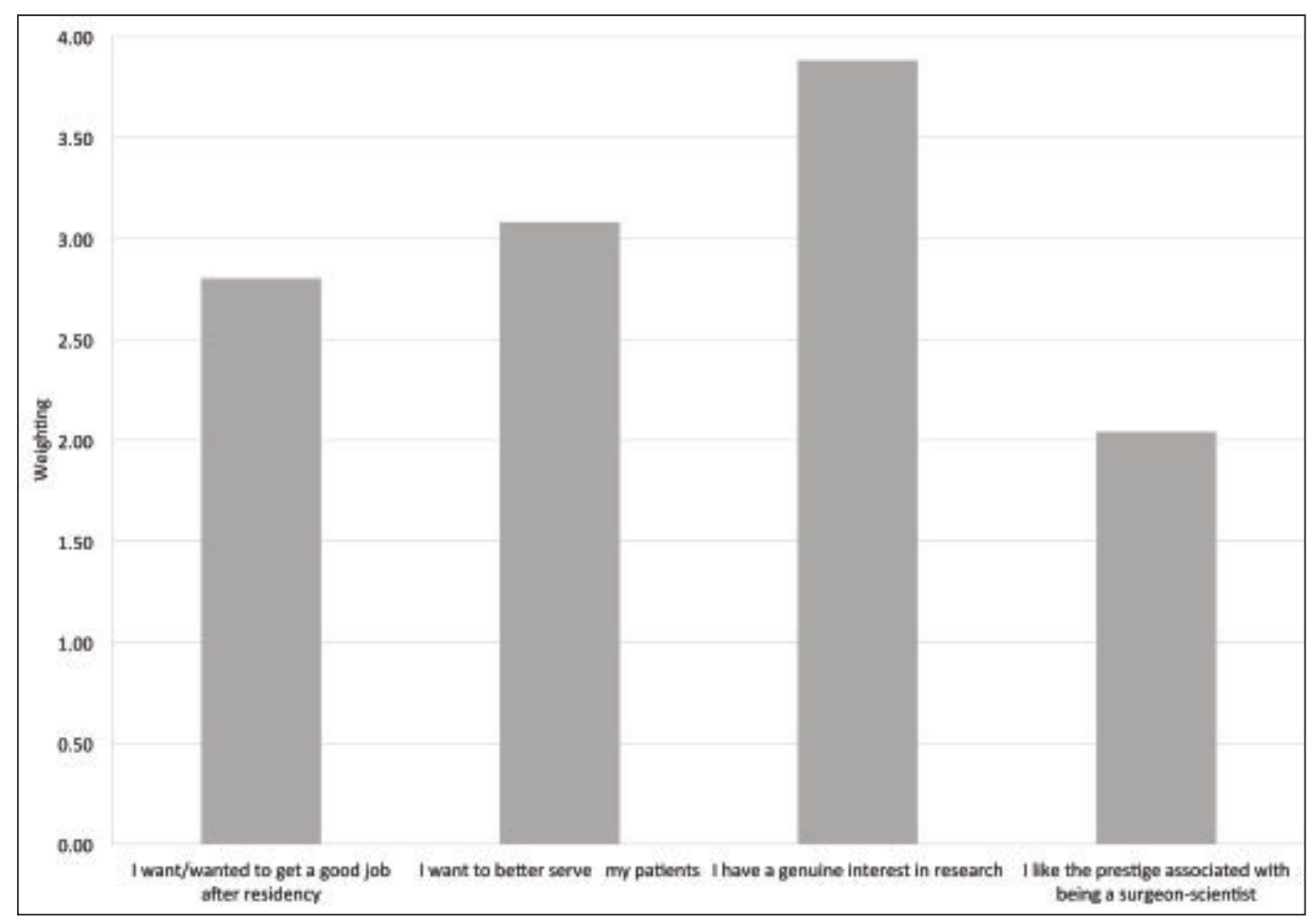

Figure 1: Relative weighting of the reasons for pursuing research as a neurosurgeon-scientist. 


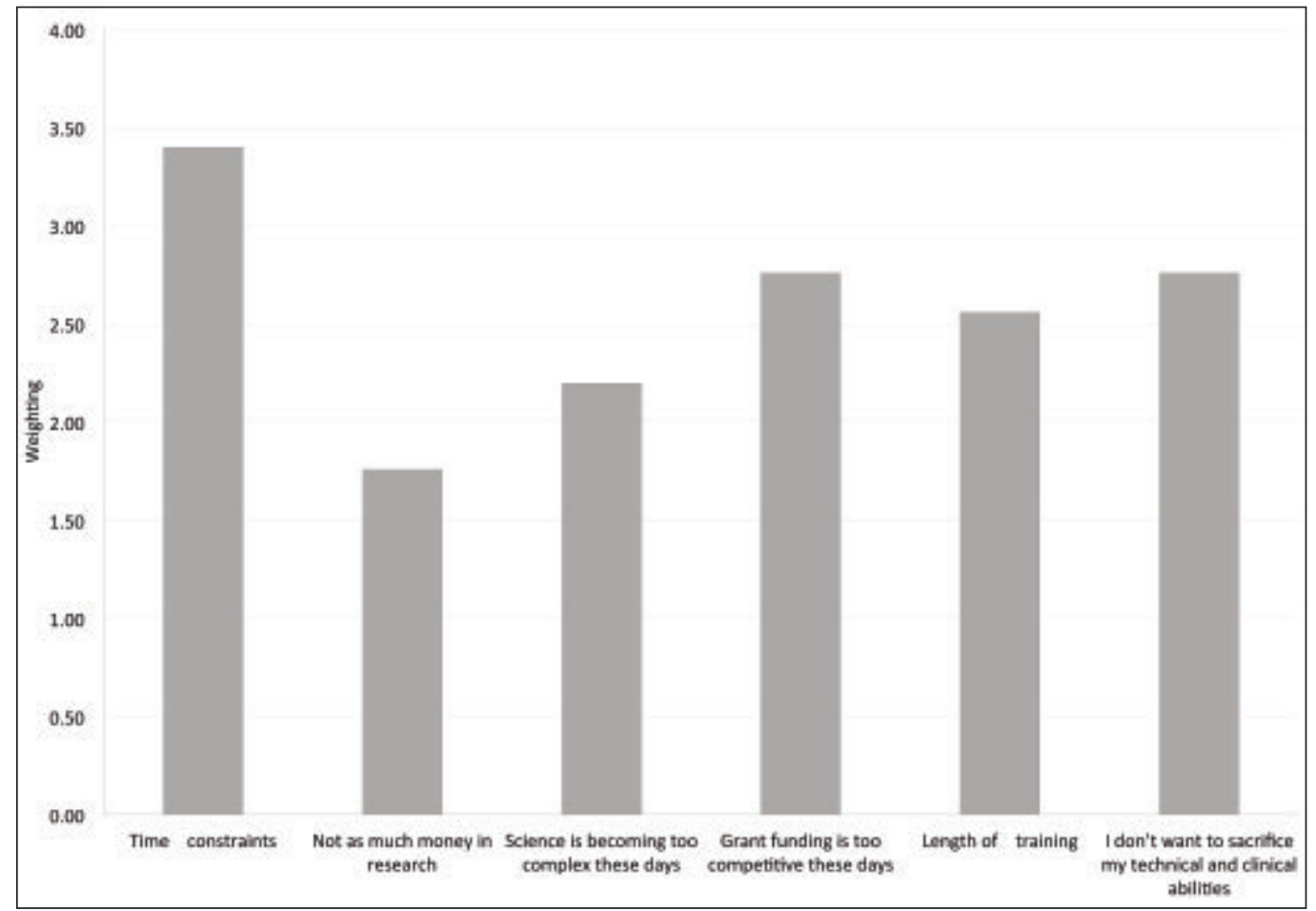

Figure 2: Relative weighting of the reasons for not pursuing research as a neurosurgeon.

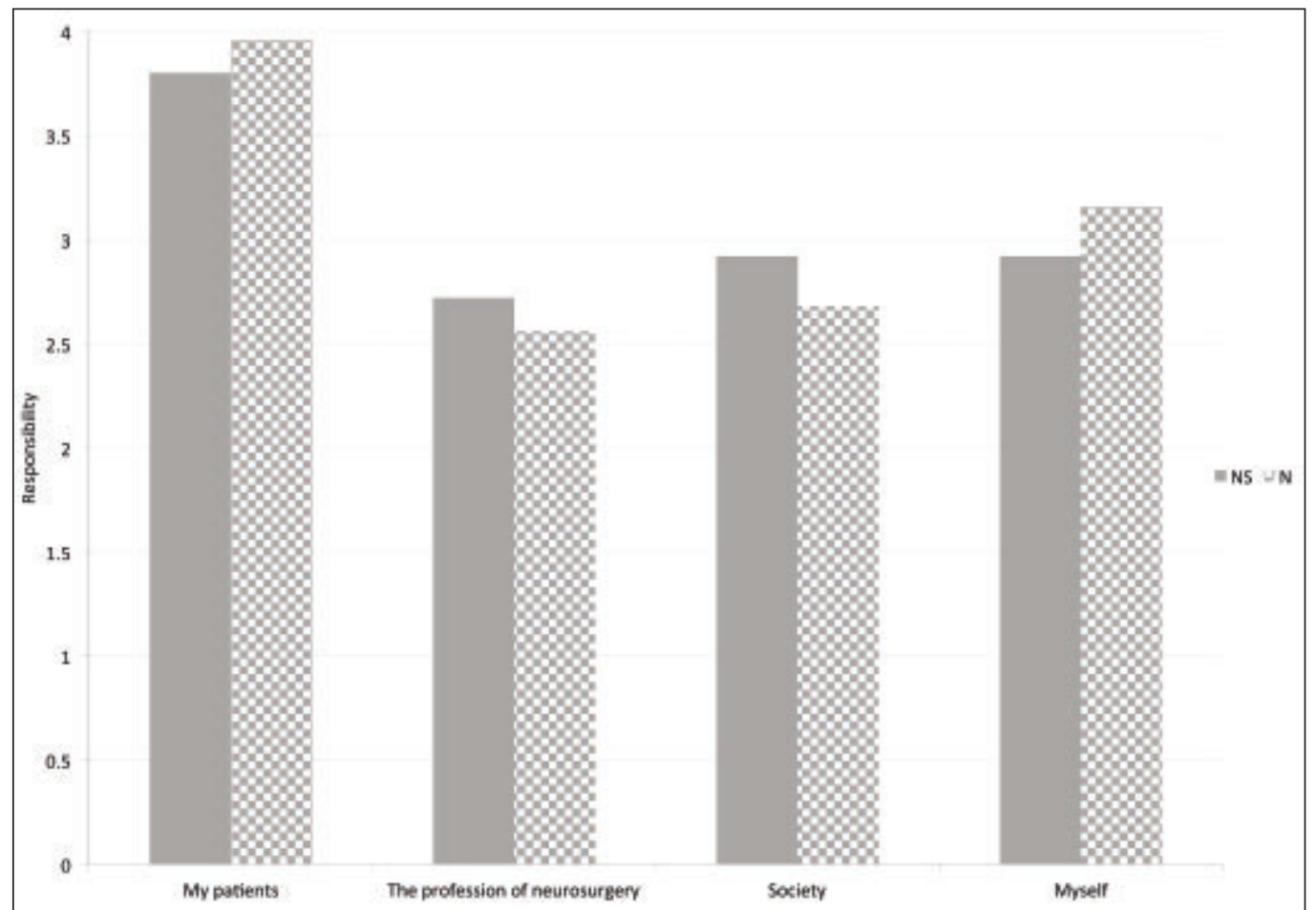

Figure 3: Relative responsibility felt towards various categories, as compared between neurosurgeons and neurosurgeon-scientists. NS: Neurosurgeon-scientists; N: Neurosurgeons 
Although more neurosurgeons $(66.7 \%)$ felt this way compared to neurosurgeon-scientists $(51.5 \%)$, this difference was not significant, $\mathrm{x}^{2}(1)=1.205, \mathrm{p}=0.272$.

With regard to the caliber of research produced by those taking on the dual role, only $33.3 \%$ of respondents $(18 / 54)$, equally divided between residents and staff, felt that most neurosurgeon-scientists produced research of great impact and significance. Interestingly, there was no significant difference between the percentage of neurosurgeon-scientists $(36.4 \%)$ and the percentage of neurosurgeons $(28.6 \%)$ who criticized the quality of research, $\mathrm{x}^{2}(1)=0.351, \mathrm{p}=0.554$.

\section{The 'ideal' versus the 'real' neurosurgeon}

All participants ranked various attributes that defined an 'ideal' neurosurgeon, with the results shown in Figure 4. As can be seen in the figure, technical skill and knowledge base ranked the highest, and research and leadership abilities ranked the lowest. One-way ANOVA showed that the weightings differed significantly across all the responses, F $(7,424)=29.23, \mathrm{p}<$ 0.001 . Bonferroni post-hoc analysis revealed several pair-wise comparisons that reached statistical significance, including research ability $(\mathrm{M}=2.57)$ being significantly lower than all other attributes, $\mathrm{p} \leq 0.002$. In fact, when asked specifically, $83.3 \%$ of respondents (45/54) did not feel that conducting research in addition to clinical duties was needed to become an 'ideal' neurosurgeon.

With these idealistic attributes in mind, the survey shifted to actual practice and asked whether most neurosurgeon-scientists were realistically able to perform good work in both clinical and research arenas simultaneously. Thirty-five of 54 (64.8\%) of resident and staff participants felt that in actuality most neurosurgeon-scientists are unable to do so, with most sacrificing some of their technical abilities at the expense of research. Sub-analysis showed that more neurosurgeons $(81.0 \%)$ shared these sentiments than did neurosurgeon-scientists $(54.6 \%)$, with the difference being statistically significant, $\mathrm{x}^{2}(1)$ $=3.92, \mathrm{p}=0.048$. Furthermore, $33.3 \%$ of respondents $(18 / 54)$ felt that neurosurgeon-scientists are unable to even perform adequately in clinical and research arenas simultaneously.

\section{Research training in neurosurgery and sub-specialization}

Forty-four of $54(81.5 \%)$ of those surveyed felt that in general, most neurosurgeons do not need a Master's or $\mathrm{PhD}$ degree, with no significant difference found between resident $(85.2 \%)$ and attending $(77.8 \%)$ opinions, $\mathrm{x}^{2}(1)=0.491, \mathrm{p}=$ 0.484. Despite this, $55.6 \%$ of respondents (30/54) possessed graduate research degrees. Of note, out of the respondents who were not neurosurgeon-scientists, $63.6 \%$ (14/22) had completed one or more years of formal research training, with nine of these having either a Master's or PhD.

Along the same lines, the survey probed for opinions regarding neurosurgeon employment at academic centers and attitudes towards manuscript publication. Forty-six of 54 (85.2\%) of respondents were in favor of academic centers employing purely clinical neurosurgeons alongside neurosurgeon-scientists, rather than hiring only neurosurgeon-scientists, with the differences between resident $(81.5 \%)$ and attending $(88.9 \%)$ respondents being insignificant, $\mathrm{x}^{2}(1)=0.587, \mathrm{p}=0.444$. Despite

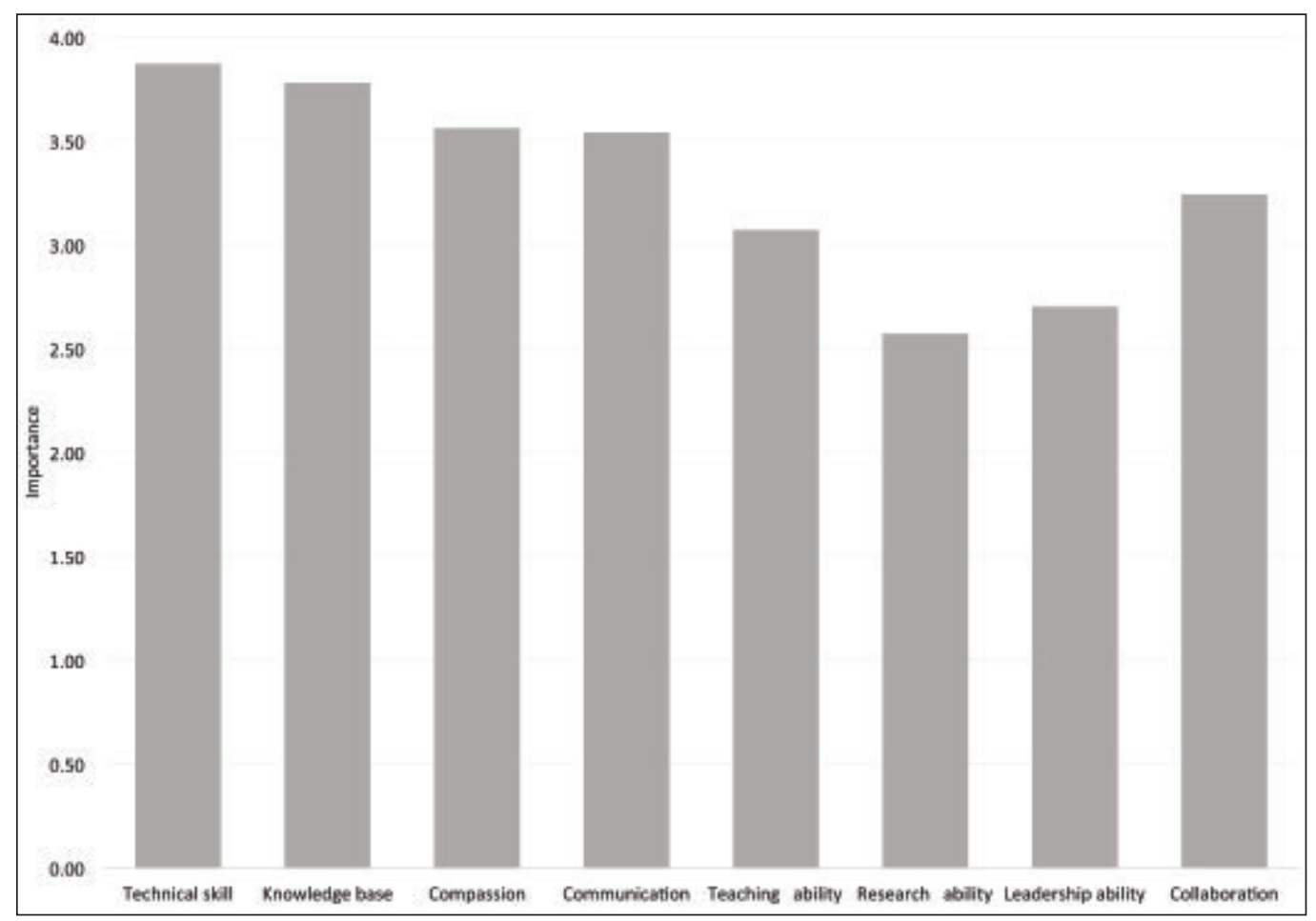

Figure 4: Relative importance of various attributes necessary to define an 'ideal' neurosurgeon 


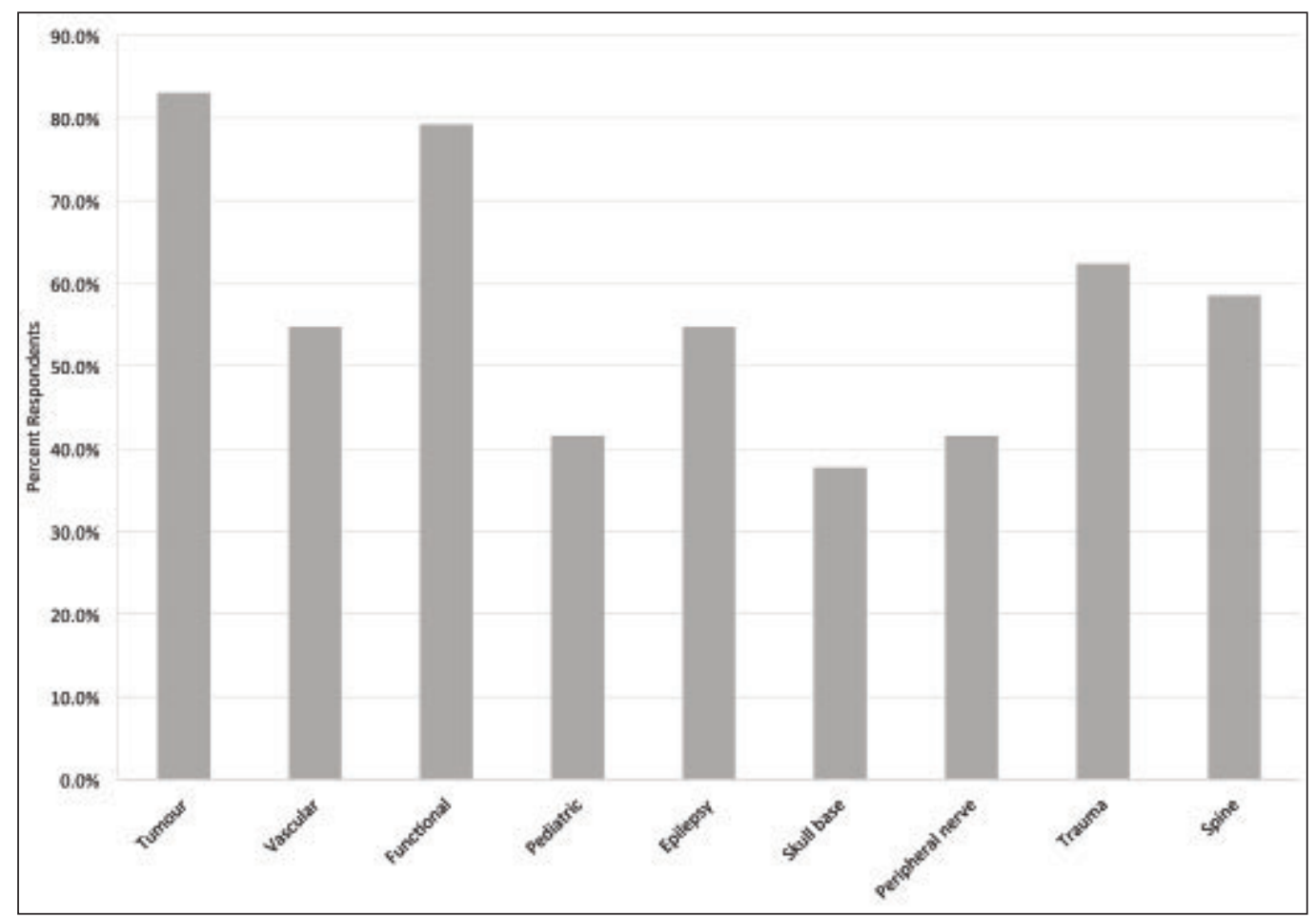

Figure 5: Percent of respondents selecting sub-specialties they felt would benefit most from the work of neurosurgeon-scientists.

these clinically oriented opinions, $77.8 \%$ of respondents (42/54) reported feeling pressure to publish journal articles. Although a larger percentage of residents $(85.2 \%)$ felt this way compared to staff $(70.3 \%)$, this difference did not reach statistical significance, $\mathrm{x}^{2}(1)=1.714, \mathrm{p}=0.190$.

All participants were then asked which sub-specialties within neurosurgery would benefit the most from the work of neurosurgeon-scientists, with the rankings shown in Figure 5. As can be seen in the figure, tumor and functional were chosen most often, and pediatrics, skull base, and peripheral nerve least often.

\section{DISCUSSION}

Performing good work in neurosurgery or neuroscience alone is a tremendous undertaking, which makes performing good work in both fields simultaneously seem almost unmanageable. In fact, this study showed that two thirds of resident and staff neurosurgeons feel that most individuals with this dual designation are unable to excel in both arenas concurrently. Despite this challenge of a dual career, a large proportion of Canadian neurosurgeons and neurosurgical residents either currently assume or aspire to assume both roles, with this study showing $60 \%$ being current or intended neurosurgeon-scientists. The reasons for this discrepancy between pro-research ideals and anti-research realities will be examined through the basic issues considered by thoughtful practitioners, as defined by Gardner ${ }^{17}$. These include the central missions and motives of practicing neurosurgeons and residents, the professional standards set forth and upheld by major stakeholders in the field, and the sentiments of identity held by neurosurgeons.

\section{Mission and motives}

Having a natural curiosity for discovery and innovation is clearly a requirement for any successful researcher, and neurosurgeon-scientists are no exception. In fact, of those surveyed, a genuine interest in research was ranked as number one in reasons for pursuing research endeavors in addition to clinical work. More surprising, perhaps, was the statistically insignificant difference between the second and third reasons, which were a desire to better serve one's patients and a desire to secure a good job after residency. Equating a noble pursuit, that of furthering knowledge to help others, with a somewhat less elegant aspiration, that of securing employment, is concerning, but brings to light the reality that research is becoming a major component of Canadian neurosurgery. Recent job shortages may be creating a shift in the sector, in that the lure of employment is transforming research from a noble, optional endeavor to one that is more practical and compulsory.

\section{Professional standards in relation to research}

Opinions regarding ideal professional standards, as investigated through this study, revealed that research ability ranked the lowest among characteristics that would embody the 'ideal' neurosurgeon. In fact, when asked specifically whether research ability was a quality essential to neurosurgery, $83 \%$ of those surveyed responded in the negative. This is similar to a study where internists ranked characteristics exemplified by outstanding individuals in their field, with research ability getting a mere $6.8 \%$ of votes ${ }^{15}$. The difference lies, however, in 
the emphasis put on research in the field of neurosurgery compared to other specialties. Ours is the only specialty where all programs require at least one year of dedicated research time during residency, two years in the United States, with many residents extending this time to pursue higher education. The reason for this emphasis on research is not entirely clear, especially since $82 \%$ of those surveyed felt that neurosurgeons did not need a graduate degree. This 'push for research' is also evident from the pressure resident and staff neurosurgeons feel to publish journal articles, with this study finding about $85 \%$ of residents and $70 \%$ of staff surgeons reporting feeling pressure to publish papers.

This drive to produce research may be misdirected as sentiments regarding the quality of investigational efforts in the field are weak. It is of concern that only about one third of respondents felt that neurosurgeon-scientists produced research of notable impact and significance. Although it would be valuable to look into how they would rate the caliber of research produced by basic scientists in the same field, as the numbers may be similar, it still raises the issue of the need to have so many neurosurgeons that are well versed in research. One possible reason is that the large majority of neurosurgery in Canada is practiced at academic centers, making higher education an inevitable reality. But, when questioned regarding the role of neurosurgeon-scientists in academic environments, $85 \%$ of those surveyed felt that these centers should employ purely clinical neurosurgeons alongside neurosurgeon-scientists. Academic centers in Canada are currently comprised of both groups, but further investigation evaluating the hiring practices of these centers over the last ten years could determine whether this mix will persist into the future, and subsequently whether the increasing number of Canadian neurosurgical residents pursuing graduate degrees is related.

Similarly, just as most respondents felt that the research produced by neurosurgeon-scientists suffered at the expense of their clinical work, $65 \%$ of those surveyed felt that neurosurgeon-scientists sacrifice some of their technical abilities at the expense of research endeavors. In fact, one third felt that dividing one's career between research and clinical domains made it very difficult to excel in both. These are troubling statistics, as clinicians and patients alike regard the quality of surgical and clinical care as the most important professional standard. One possible solution to this pitfall is subspecialization, as backed by Rutka and Wallace ${ }^{18}$. Through subspecialization, neurosurgeons restrict surgical activities to a focused area that mirrors their investigative work, and are therefore able to maintain a significant case load while still devoting sufficient time to research.

Ultimately, there are ample reasons to preserve the research component of neurosurgical training. Research training, whether under the guise of formal graduate work or not, provides exposure to different perspectives and ways of thinking, and few would argue that experiences gained during their dedicated research time were not worthwhile. However, this study revealed that of the neurosurgeons who do not conduct research, $64 \%$ $(14 / 22)$ have completed more than one year of research training, and of these $64 \%$, two thirds $(9 / 14)$ have graduate research degrees. In other words, a substantial number of neurosurgeons dedicate a considerable amount of time to research training, but despite the benefits of this training, do not actively conduct research. Several reasons could account for this discrepancy, such as those shown in Figure 2. Regardless, alternatives to one person taking on the roles of both researcher and surgeon are required, preferably while maintaining our sense of identity as neurosurgeons.

\section{Identity}

Like most doctors, neurosurgeons are primarily concerned with the well-being of their patients, regardless of other interests such as research. In fact, when questioned as to professional responsibilities, this study found that almost all neurosurgeons felt most responsible to their patients, with no significant difference between the opinions of scientists and pure clinicians. Adopting novel research models while preserving this sense of identity is difficult but vital to the furthering of the profession.

One such alternative model is collaboration, and it has been in the making for decades. In the early 1980's, Langfitt ${ }^{19}$ predicted that basic science research for improving patient care will remain in the realm of the neurosurgeon, but the 90's saw a steady decrease in the number of medical students expressing an interest in research ${ }^{20,21}$, and fewer young clinician-scientists obtaining federal grant support ${ }^{22}$. Recent trends show that these numbers may be leveling out ${ }^{23,24}$, but one explanation for this shift could be that physicians are realizing that significant advancements in today's research domains are often the result of the merging of expertise from multiple fields ${ }^{25}$. Neurosurgeons in this study seem to agree with this philosophy in that $87 \%$ of those surveyed felt that surgeons who collaborate with basic scientists to conduct research are equally or more likely to obtain meaningful results compared to neurosurgeon-scientists conducting the same research single-handedly. These views support those expressed by Black when he wrote that the traditional all-encompassing neurosurgeon will soon be a thing of the past, and that newer generations will thrive on collaboration and flexibility ${ }^{8}$. In fact, these collaboration paradigms are now permeating the various clinical and basic sciences $^{26}$ and causing some centers to re-examine the fundamental concept of academic medicine ${ }^{8,27}$.

\section{Limitations and future directions}

The main limitation of this study is that statements made in the survey and reported on in this manuscript refer to 'most' neurosurgeon-scientists, and are therefore generalizations. There will always be a few exemplary individuals who truly excel in both research and surgery simultaneously, making the conclusions drawn from this study inapplicable to every situation. However, the purpose of this study was not to evaluate the work of this select few, but rather to compile opinions that can be taken to represent the general view in the field on the work of neurosurgeon-scientists in general.

The need to obtain this general view gives rise to the second limitation: that the opinions of residents and staff neurosurgeons were often pooled, a tactic that may potentially bias the results towards a more idealistic view of the profession, a view that is arguably more common among residents. This was done for two reasons: First, residents are greatly influenced by pressures to conduct research, perhaps more so than staff surgeons, as they are trying to conform to changing views of the profession and secure employment upon completion of training. Therefore, 
considering their opinions as equivalent to those of staff surgeons is imperative as it allows them an equal representation in the overall results, results that may directly shape their future careers. Second, resident and staff respondent numbers were insufficient to produce significant results when analyzed separately.

As this study was qualitative in nature, future study using less abstract measures could attempt to quantify 'good work' in neurosurgery research. Although controversial, measures such as publication record and impact factors could be compared between neurosurgeon-scientists and basic scientists to provide a more concrete stance on the issue. However, the preliminary opinion data acquired in this study can serve as a guide to tailor future studies in assessing more tangible measures of research and clinical excellence in the field.

Furthermore, it is important to realize that this study is specific to Canada, and while outcomes and sentiments may mirror those present in other public health care systems, the results are difficult to extrapolate to other countries and health care organizations. It would be useful, however, to determine whether these Canadian research sentiments are mirrored in the United States, although without the centralized healthcare system that exists in Canada, financial issues would likely play a much larger role. Also, it would be interesting to see how the demographics and opinions regarding research in neurosurgery are comparable to those of other surgical and internal medicine specialties within Canada.

\section{CONCLusion}

This study aimed to determine whether it is possible for neurosurgeon-scientists to perform good work in both neurosurgery and research simultaneously, or whether one field suffers at the expense of the other. Through the opinions of practicing resident and staff neurosurgeons in Canada, it was revealed that it is possible to do good work in both arenas simultaneously, but in reality most neurosurgeon-scientists do not achieve this ideal as it is very difficult to attain. Alternatives to this dual career, such as collaboration between surgeons and pure scientists for example, may help bridge the gap between clinical neurosurgery and research neuroscience.

\section{REFERENCES}

1. Wilkins RH. Science in neurosurgery: the importance of the scientific method. Neurosurgery. 1998 Apr;42(4):687-91.

2. Davis RA, Cunningham PS. Creative thought in neurosurgical research: the value of citation analysis. Neurosurgery. 1990 Feb; 26(2):345-53.

3. Hurwitz SR, Buckwalter JA. The orthopaedic surgeon scientist: an endangered species? J Orthop Res. 1999 Mar;17(2):155-6.

4. Kreider T. Medical training versus scientific training [Internet]. Science-Based Medicine: Medical Academia, Science and Medicine; 2009 [cited 2013 Feb 14]. Available from: http://www.sciencebasedmedicine.org/index.php/medicaltraining-versus-scientific-training/

5. Vates GE, Kim DH, Day AL. The neurosurgeon as clinicianscientist: the fundamentals. Clin Neurosurg. 2004;51:53-8.

6. Schrier RW. Ensuring the survival of the clinician-scientist. Kidney Blood Press Res. 1998;21(2-4):211-2.

7. Skenderis BS, 2nd, Rustum YM, Petrelli NJ. Basic science research in postgraduate surgical training: difficulties encountered by clinical scientists. J Cancer Educ. 1997;12(4):245-8.
8. Black PM. Challenges in contemporary academic neurosurgery. Neurosurgery. 2006 Mar;58(3):419-25; discussion -25.

9. McLone DG. A boutique practice or specialist to the world. Childs Nerv Syst. 1998 Nov;14(11):630-5.

10. Bergland RM. Neurosurgery may die. N Engl J Med. 1973 May 17; 288(20):1043-6.

11. Friedlander R. The perfect storm: current status of research in neurosurgery. Congress Qrtly. 2008;9(1):38-41.

12. Wagner P, Hendrich J, Moseley G, Hudson V. Defining medical professionalism: a qualitative study. Med Educ. 2007 Mar;41(3): 288-94.

13. Leahy M, Cullen W, Bury G. "What makes a good doctor?" A cross sectional survey of public opinion. Ir Med J. 2003 Feb;96(2): $38-41$.

14. Patel G. What makes a good doctor? Br J Gen Pract. 2007 Mar;57 (536):244-5.

15. Eva KW, Lohfeld L, Dhaliwal G, Mylopoulos M, Cook D, Norman G. Modern conceptions of elite medical practice among internal medicine faculty members. Acad Med. 2011;86(10):S50-4.

16. Sonnert G. What makes a good scientist?: Determinants of peer evaluation among biologists. Soc Stud Sci. 1995;25(1):35-55.

17. Gardner HC, M.; Damon W. Good work: when excellence and ethics meet. New York: Basic Books; 2001.

18. Rutka JT, Wallace C. Excellence in neurosurgery program building: enhancing the academic mission. Clin Neurosurg. 2010;57: 100-11.

19. Langfitt TW. Research and training in the neurosurgical sciences. With comments on some key issues that confront neurosurgery. J Neurosurg. 1982 Dec;57(6):733-8.

20. Guelich JM, Singer BH, Castro MC, Rosenberg LE. A gender gap in the next generation of physician-scientists: medical student interest and participation in research. J Investig Med. 2002 Nov; 50(6):412-8.

21. Rosenberg LE. The physician-scientist: an essential--and fragile-link in the medical research chain. J Clin Invest. 1999 Jun;103 (12):1621-6.

22. Zemlo TR, Garrison HH, Partridge NC, Ley TJ. The physicianscientist: career issues and challenges at the year 2000. Faseb J. $2000 \mathrm{Feb} ; 14(2): 221-30$.

23. Ley TJ, Rosenberg LE. The physician-scientist career pipeline in 2005: build it, and they will come. JAMA. 2005 Sep 21;294(11): 1343-51.

24. Zusman EE. Key factors contributing to the success of clinician investigators: converting $\mathrm{K} 08$ and $\mathrm{K} 23$ to R01 awards. Neurosurgery. 2010 Apr;66(4):N14-5.

25. Abele J. The collaboration paradox: why collaborations seem so common but are actually very rare. Xconomy [Internet]. 2008 Jul [cited 2013 Feb 14]:[about 9 p.]. Available from: http://www.xconomy.com/boston/2008/07/07/the-collaborationparadox-why-so-many-leaders-sabotage-their-owncollaborations-and-some-tactics-for-getting-things-right/? single_page $=$ true

26. Moore FD. Ethical problems special to surgery: surgical teaching, surgical innovation, and the surgeon in managed care. Arch Surg. 2000 Jan;135(1):14-6.

27. Howell LP, Servis G, Bonham A. Multigenerational challenges in academic medicine: UCDavis's responses. Acad Med. 2005 Jun; 80(6):527-32. 